\title{
Beyond a diagnosis: The experience of depression among clinically-referred adolescents
}

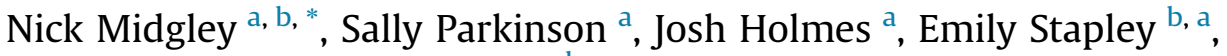 \\ Virginia Eatough ${ }^{c}$, Mary Target ${ }^{\mathrm{b}}$ \\ a Anna Freud Centre, 12 Maresfield Gardens, London, NW3 5SU, UK \\ ${ }^{\mathrm{b}}$ Research Dept of Clinical, Educational and Health Psychology, University College London, 1-19 Torrington Place, London, WC1E 7HB, UK \\ ${ }^{\mathrm{c}}$ Department of Psychological Sciences, Birkbeck College, University of London, Malet Street, London, WC1E 7HX, UK
}

\section{A R T I C L E I N F O}

\section{Article history:}

Available online $\mathrm{xxx}$

\section{Keywords:}

Adolescence

Depression

Lived experience

Diagnosis

Qualitative

\begin{abstract}
A B S T R A C T
Policy-makers have identified an urgent need to improve our ability to detect and diagnose depression in adolescents. This study aims to explore the lived experience of depression in clinically referred adolescents. 77 adolescents, aged between 11 and 17 with moderate to severe depression, were interviewed as part of a randomised controlled trial, using the Expectations of Therapy Interview. Data were analysed qualitatively using framework analysis, with a focus on how the adolescents spoke about their depression. The study identified five themes: 1) Misery, despair and tears; 2) Anger and violence towards self and others; 3) A bleak view of everything; 4) Isolation and cutting off from the world; and 5) The impact on education. Researchers and policy-makers need to develop an understanding of depression grounded in the experiences of adolescents to improve detection and diagnosis of depression.

() 2015 The Foundation for Professionals in Services for Adolescents. Published by Elsevier
\end{abstract} Ltd. All rights reserved.

'I just feel lonely, like nobody understands what I'm going through'

Steven, 17.

Depression in children and adolescents is recognised as 'a broad and heterogeneous diagnostic grouping' (NICE, 2013), and policy makers in both Europe and the US have identified an urgent need to improve our ability to detect and diagnose, both among professionals in primary care and community settings, as well as by mental health professionals working in specialist child and adolescent mental health services (CAMHS).

Studies have demonstrated that most cases of depression in adolescence go undetected (Kessler, Avenevoli, \& Ries Merikangas, 2001; Martinez, Reynolds, \& Howe, 2006), leading policy makers to put an increasing focus on detection. For example, the National Institute for Health and Care Excellence (NICE), which provides guidance, quality standards and information services for public health and social care in the UK, identified the need for greater detection as early as 2005 (NICE, 2005), yet there is little evidence to date of significant improvements. This may be because of issues such as stigma regarding mental health, poor parent-child communication, and the lack of systematic early identification programmes or routine use of

\footnotetext{
* Corresponding author. Anna Freud Centre, 12 Maresfield Gardens, London, NW3 5SU, UK. Tel.: +44 2077942313.

E-mail address: Nick.Midgley@annafreud.org (N. Midgley).
} 
screening tools within services (Rey, Grayson, Mojarrad, \& Walter, 2002; Williams, O'Connor, Eder, \& Whitlock, 2009). In addition, warning signs of depression, such as persistent change in mood, loss of interest and enjoyment in activities and rebellious behaviour, can sometimes be dismissed as 'teenage behaviour' (Dundon, 2006).

How depression should be understood in the context of 'normal' adolescent development has been a topic of debate for many years. Until the 1970s, episodes of depressive crisis were considered a usual part of adolescent development, and there was no recognised psychiatric diagnosis of child or adolescent depression in early versions of the Diagnostic and Statistical Manual (DSM). This changed with the publication of DSM-III in 1980 (APA, 1980), at a time when developmental psychologists such as Michael Rutter (1980) were establishing that most adolescents' lives were not characterised by the 'storm and stress' that some earlier theorists, such as Stanley Hall (1904), had assumed. Whilst recognising that the process of identity development in adolescence may well include typical feelings of self-doubt, loneliness and sadness, recent empirical studies have suggested that only about $2.8 \%$ of children under the age of 13 , and $5.6 \%$ of those between 13 and 18 , meet diagnostic criteria for a depressive disorder (Costello, Erkanli, \& Angold, 2006) - with depression twice as common among girls than boys after the age of 13 (Birmaher et al., 2007).

According to the 5th edition of DSM (APA, 2013), a diagnosis of major depressive disorder in young people depends on signs of a pervasive shift towards sadness, irritability, loss of interest or loss of pleasure over a minimum of a two week period. To meet diagnostic threshold, these symptoms need to be markedly different from how the young person usually is, and to be leading to clear impairment in the young person's life. There is also an increasing recognition that children and adolescents suffering from depression are also likely to have a range of other difficulties, with levels of co-morbidity rated as between 50 and 80\% (Birmaher et al., 2007). Depressed adolescents are most likely to also suffer from some form of anxiety disorder, but may also present with disruptive disorders, substance abuse and emerging personality disorder. Although there are relatively high rates of recovery from depressive episodes (which last on average between 7 and 9 months in young people), there is also a very high level of relapse, with as many as 70\% of young people who experience depression having a further episode of depression within 5 years (Richmond \& Rosen, 2005). The long-term consequences of depression in adolescence are also striking, with an increased risk of self-harm, suicide, depression, physical illness, substance misuse, and interpersonal problems in adulthood (Weissman et al., 1999).

Despite our increasing knowledge about the prevalence and course of adolescent depression, it is widely recognised that the nature of adolescent depression is still not sufficiently understood, with the psychiatric concept of 'depressive disorders' covering a heterogeneous range of difficulties. Young people suffering from depression themselves can often feel that no one understands them, as illustrated by the quotation at the start of this paper. Lachal et al. (2012) note that the Diagnostic and Statistical Manual (DSM) criteria for depression do not make reference to subjective experience, despite this being central to depression. We therefore need to develop an understanding of depression that is grounded in young people's experiences; without this, there is a danger that it will continue to be under-diagnosed, misdiagnosed or left untreated (Cicchetti \& Toth, 1998; Lachal et al., 2012).

Due to the relatively recent recognition of child and adolescent depression as a psychiatric phenomenon, Studies only began to explore the idea that features of adolescent depression may differ from adult depression since the 1980's (Crowe, Ward, Dunnachie, \& Roberts, 2006). On the basis of a series of studies, DSM-IV-TR concluded that the core symptoms of a major depressive episode are the same for children and adolescents, whilst recognising that certain symptoms may be more or less prominent at different ages (American Psychiatric Association, 2000). Most significantly, 'irritability' has been identified since DSM-III as one of the core characteristics of depression in adolescence, alongside low mood (American Psychiatric Association, 1980). A 2009 review article in Psychiatry concluded that depressed adolescents are 'less likely than adults to explicitly complain of feeling depressed and unlikely to exhibit melancholic symptoms', whilst being 'more likely than adults to exhibit mood lability or irritability and display indirect or behavioural manifestations of disturbed mood' (Cook, Peterson, \& Sheldon, 2009, p.19).

Despite these conclusions, a number of questions remain unanswered about the nature of depression in adolescence. Crowe and colleagues, in a study from New Zealand, concluded that both the manifestation and the prominence of symptoms may differ between adolescents and adults, with irritability and decreased concentration being the most frequently reported symptoms in adolescents, followed by social withdrawal, fatigue, psychomotor retardation, depressed mood, hopelessness and helplessness, and insomnia (Crowe et al., 2006). Among characteristics not included within the diagnostic features of depression, social withdrawal was the most common symptom among boys, and loneliness among girls. The finding that irritability was more often reported than low mood confirmed the findings of earlier studies (e.g. Mueller \& Orvaschel, 1997), and it was noted that the significance of irritability increased with the severity of depression. Yet, despite the apparent centrality of irritability to adolescent depression, Stringaris and colleagues noted that empirical data on the prevalence and correlates of irritability in depressed youth is lacking, and little is known about whether irritability is associated with outcomes (Stringaris, Maughan, Copeland, Costello, \& Angold, 2013). Irritability and isolation seem to be important aspects the nature of depression in adolescents. Other issues that seem most pertinent for adolescents include problems with sleep, difficulties at school and with peers, and self-harm.

The studies reported above are limited by the fact that they used standardised measures of depression which predetermine which features they can report on. Although these measures have usually gone through a process of development that includes focus groups and input from young people, the measures often start as adaptations of tools widely used in adult literature, which may carry over certain 'adultomorphic' ideas of young people as 'miniature adults' into the definitions of adolescent depression. Giving young service users a voice in describing their experience of depression can help to improve 
our ability to recognise, assess and treat depression (Farmer, 2002), by opening the possibility of developing a more complete picture of the phenomenology of youth depression. Yet to date, few studies report on young people's experiences of depression. Indeed, Dundon's (2006) metasynthesis examining the experience of depression in adolescence found only six qualitative studies, with sample sizes ranging from 4 to 48 participants; and only a few studies of the phenomenology of adolescence from the young person's perspective have been published since that date (e.g. Lachal et al., 2012; McCann, Lubman, \& Clark, 2012). These studies have highlighted aspects of depression which have been somewhat neglected in the literature, such as the experience of social isolation and withdrawal (which is not a core diagnostic feature of depression in DSM-5 or ICD-10) (American Psychiatric Association, 2013; World Health Organization, 1993), or the sense of confusion that many young people describe in relation to their depression (which may be an important consideration when planning prevention and intervention programmes). Questions remain about whether findings from these studies are transferrable to a UK setting, or to younger adolescents, whose experience may be different to older adolescents.

The aim of the current study is therefore to build on previous studies by exploring the experience of depression in a sample of young people aged between 11 and 17, who have been clinically referred to child and adolescent mental health services for treatment for depression, but have yet to receive therapeutic help, beyond an initial assessment meeting. Conducted as part of a large pragmatic, randomised controlled trial (RCT) currently taking place in the UK (Goodyer et al., 2011), this study was able to avoid some of the limitations of studies based on pre-existing measures of depression (which are often based on measures developed for adult populations), whilst at the same time including a far larger sample of young people than is common in qualitative studies. This large sample will enable us to develop a robust analytic structure based on the experience of young people with depression.

\section{Methods}

Setting for the study

A large randomised controlled trial, the Improving Mood with Psychoanalytic and Cognitive Therapies (IMPACT) study, is currently taking place across the UK (Goodyer et al., 2011). IMPACT is comparing the effectiveness of three therapeutic approaches - cognitive behavioural therapy (CBT), short-term psychodynamic psychotherapy (STPP) and specialist clinical care (SCC) - for adolescent depression. IMPACT-My Experience (IMPACT-ME) is a qualitative, longitudinal study in which interviews are conducted with the young people, their parents, and therapists taking part in the IMPACT trial at three timepoints - before and after therapy, and at one-year follow-up (see Midgley, Ansaldo, \& Target, 2014, for full details of the IMPACT-ME study in relation to IMPACT). The aim of this paper, which draws on data from only the baseline (pre-therapy) interviews in one region of the study (London), is to explore the experience of depression in this sub-group of adolescents who were referred to child and adolescent mental health services in the UK and were recruited into the IMPACT trial.

\section{Sample and data collection}

Potential participants were taking part in the London arm of the IMPACT trial (Goodyer et al., 2011), and had been referred to one of five mental health services in London involved in the trial. Inclusion criteria for the trial were diagnoses of unipolar depression with moderate to severe impairment and aged 11-17 years, as rated on the KSADS-PL (Kaufman et al., 1997). Exclusion criteria were generalised learning difficulties, pervasive developmental disorder, pregnancy and primary diagnosis of bipolar Type I, schizophrenia and eating disorders.

After one of the research assistants had completed the baseline assessment, if eligible, participants were randomised to a treatment arm in the study, and all those recruited between September 2011 and January 2013 were invited to participate in IMPACT-ME. Of eligible participants ( $N=80,85 \%)$, two participants did not complete the qualitative interview due to time constraints (to ensure the structured diagnostic measures were completed for the trial itself) and one participant withdrew their data from the study. The present study is therefore based on the interviews of 77 participants. These young people (22 males; 55 females) had an age range of $11-1711-17(M=15.86, S D=1.77) .50 \%$ of participants described their ethnicity as white British, $14 \%$ as mixed, $7 \%$ as black/black British, 5\% as Asian/Asian British, and $8 \%$ as 'any other ethnic group'. Ethnicity data was missing for $16 \%$ of the sample. Scores on the Mood and Feelings Questionnaire (MFQ; Angold, Costello, Pickles, \& Winder, 1987), a 33-item, standardised, self-rated questionnaire of depressive symptoms, ranged from 20 to 65 $(M=47.01, S D=10.45)$, where a score of 28 and above has been used to discriminate adolescents with major depression (Angold et al., 1987). Based on K-SADS-PL ratings, the number of co-morbid diagnoses ranged between 0 and 5 ( $M=0.91$, $S D=1.24)$. The most common were generalised anxiety disorder (24.68\%); avoidant disorder (18.18\%); oppositional defiant disorder (14.29\%); phobias (12.99\%); and PTSD (6.49\%).

The Expectations of Therapy Interview (ETI, Midgley et al., 2011) was developed for the present study, drawing on elements of Elliott's Change Interview (Elliott, Slatick, \& Urman, 2001) and Werbart's Private Theories Interview (Werbart \& Levander, 2005). All research assistants working on the IMPACT trial were post-graduate psychologists, and were given a half-day training session in semi-structured interviewing, and offered feedback on interviewing technique following their initial interviews with young people. At the start of the Expectations of Therapy Interview, the researcher explains that they are interested in hearing about things in the participant's own words and that there are no right or wrong answers. The semistructured interview explores three key areas: the difficulties that brought young people to child and adolescent mental 
health services; how they understand those difficulties; and their expectations of therapy. The Expectations of Therapy Interview was carried out at the beginning of the baseline assessment; this gave participants the chance to tell their story in their own words, before the structured diagnostic measures were conducted. As there was a large battery of assessment measures used in the trial, this interview was designed to be relatively brief (10-15 min long). In practice, interviews ranged in length from 4 to $37 \mathrm{~min}$. Young people were given the opportunity to choose their own pseudonym, which are used in the reported findings. Where participants did not wish to choose their own pseudonym, the research team assigned them a pseudonym. All interviews were transcribed verbatim.

\section{Data analysis}

Framework Analysis was used due to the large sample size in this study, to provide a form of data management (Ritchie \& Spencer, 1994). Framework Analysis is a method of qualitative data analysis that was originally developed in the context of social policy research in the UK, but has recently becoming increasingly popular in the fields of nursing and psychology (e.g. Johnston, Milligan, Foster, \& Kearney, 2012). Sitting within the family of broadly 'thematic' approaches, Framework Analysis provides a flexible but structured approach to data management and data analysis, which is especially suitable for studies where there is a specific research focus, a relatively large amount of qualitative data that needs to be managed, and where a team is working together on the process of data analysis. The approach has also been integrated with the NVivo 10 qualitative software package (Bazeley \& Jackson, 2013), which was used in this study. For this study, the Framework Analysis was carried out by the core IMPACT-ME team (the authors of this paper), which included two academics (NM and VE) with considerable experience of qualitative data analysis. We followed the five stages of Framework Analysis, as outlined by Ritchie and Spencer (1994).

i. Familiarising ourselves with the data, through listening to interviews, reading transcripts and data analysis meetings;

ii. Developing a framework through which our data could be organised;

iii. Indexing the data, through systematically coding each 'chunk' of text from the transcripts to one (or more) of the categories in the framework;

iv. Charting the data which involves summarising the data in each category for each participant into a table;

v. Mapping and interpretation (the analytic phase of data analysis).

The whole team listened separately and together to a series of individual Expectations of Therapy Interviews, in order to familiarise ourselves with the data (stage one) and then met as a team over several weeks in order to develop the initial framework (stage two). Some preliminary attempts to index the data led to further refinement of the framework, which were reviewed by the research team until a stable and robust framework had been developed. Once all of the interviews had been coded to the framework (stages three and four), we had a data summary for each category and participant. This provided us with a more manageable dataset for the next stage of our data analysis (stage five). Two members of the team (NM and SP) individually explored the data that had been charted, and then discussed them looking for similarities and differences in the data. We explored patterns in the data, and began to develop a set of themes to capture young people's experiences of depression. Having developed such 'patterns of meaning' (Smith, Flowers, \& Larkin, 2009) based on the joint analysis of the first 40 interviews, we moved to a more deductive approach, where we tested how the emerging themes fitted with the remaining 37 interviews. This led to further refining of our themes, which were again discussed with the whole research team, thereby increasing our confidence in the robustness of our thematic structure to encapsulate the range of experience described by the participants in our study. (For a more detailed account of the process of conducting a Framework Analysis, see Ward, Furber, Tierney, \& Swallow, 2013).

Ethical issues

The study protocol was approved by Cambridgeshire 2 Research Ethics Committee, Addenbrookes Hospital Cambridge, UK (REC Ref: 09/H0308/137), and informed written consent was obtained from all participants in the study, including parental consent for those participants under 16 years old. In order to protect confidentiality, identifiable details are excluded or disguised.

\section{Findings}

Five main aspects of the experience of depression were identified using framework analysis: 1) Misery, despair and tears; 2) Anger and violence towards self and others; 3) A bleak view of everything; 4) Isolation and cutting off from the world; and

5) The impact on education.

Although these five themes have areas of conceptual overlap, they represent a mapping of the key elements of the experience of depression that our participants articulated. Certain topics were included in more than one theme depending on what the young person was trying to express. For example, some statements about self-harming behaviour appeared to be linked to the theme of 'misery, despair and tears', whereas at other times a young person would speak about self-harming behaviour in the 
context of 'anger and violence towards self and others'. In the context of a thematic approach such as Framework Analysis, these categorisations are not mutually exclusive. Likewise, being depressed wasn't a unitary thing for these young people - there was variety across participants, but also changes over time for each individual. Although not all aspects of depression were found in each interview, the five themes were the most salient themes for the group as a whole, and in the narrative report of these themes we describe where there was convergence and divergence in young people's experiences. Extracts from the interviews are followed by the participants pseudonym and their age at the start of the study, in brackets. In order to give some indication of frequency of the experiences described, we have used the following system in reporting the findings:

Most - this finding was based on data from 60 or more of the 77 interviews

Many - this finding was based on data from 33 to 59 of the 77 interviews

Some - this finding was based on data from 15 to 37 of the 77 interviews

A few - this finding was based on data from less than 14 of the 77 interviews

Theme One: Misery, despair and tears: 'I have never been that happy with my life, never ...' (Freddy, 17)

When asked to describe how they were feeling, the words 'sad', 'upset', 'depressed', 'low', 'miserable', 'down' and 'stressed' came up repeatedly. 'I just don't know when was [the] last time I felt happy', said Hannah (16). The sense of being 'as sad as someone can be' (Harriet, 17) was apparent - not only in what the young people said, but also in how they spoke; in quiet or flat voices, sometimes leaving long silences or quietly crying as they spoke.

Young people described ways in which their feelings of sadness and misery were expressed in bodily terms - sometimes through feeling physically sick (e.g. Vicky, 17), as 'a sort of dragging feeling' (Jake, 17) or as Hannah (16) put it, as a 'suffocating feeling in my chest'. Some described showing their sadness and despair through crying; 'I was just like crying and sob sobbing - I was just I kept crying ... I was like pleading for help' (Freddy, 17). Mitch (female, 17) spoke about how the crying would often be unexpected, as she would 'cry for like no reason, but nothing's happened or anything like that'. Crying was sometimes associated with physical tiredness or a general sense of fatigue or exhaustion. Freddy (17), for example, spoke of how he was 'always really, really miserable':

I used to cry every day for the past year and that made me really physically tired as well ... I feel so negative about everything ... disappointed, sad, angry - just all these unwanted emotions ... I have never been happy with my life, never ...

In a few cases, self-harm appeared to represent a physical expression of their sense of despair. Dylan (15), for example, spoke about an incident 'which caused everything to collapse and I ended up slitting most of my wrist up'. For others, selfharm seemed to be a way of managing feelings of despair, rather than as an expression of despair. Young people spoke about using alcohol and drugs, and for a few young people, this seemed to go beyond adolescent exploration, and parallelled the way in which they used self-harm to manage their feeling states. For example, Sabrina (17) spoke about the way in which she would drink alcohol; 'I do kind of drink into oblivion ... I guess it's just another way of release'. For Sabrina, drinking alcohol seemed to have a similar function to her self-harm, as she went on to explain why banging her head against the wall was a way of numbing herself:

It's a temporary measure to just continue with my lesson or whatever ... I sort of do it when I'm feeling like if I don't release something it will keep building up and I might actually do something that would really, really upset my family or friends - so I sort of feel sort of like a mini catharsis I suppose.

Some young people imagined not being here anymore and not living with this pain. Young people spoke about 'just feeling [like] not existing anymore' (Harriet, 17). 'I just picture myself in a coffin', explained Hayley (17), whilst Brian (12) described how he 'suddenly felt I have had enough of my life'. For some young people, this sadness and despair extended to thoughts of death, such as Oliver (14), who described the conflict between thoughts of ending his life alongside his desire to continue to live:

If I am by myself I might think about how, if I did, I'd kill myself. Like once was like 'ah, I might drown myself so then like I filled up [the] bath and I was like, but then I thought about it - I didn't think - I was like 'ah', I came to see where life goes for a bit before I try this so I haven't like tried to kill myself again.

Young people's expressions of sadness or despair sometimes resulted in others realising that they needed help. Sabrina (17), for example, had jumped from a window at a party, and ended up being taken to hospital, where she saw a psychiatrist for the first time. Hannah (16) spoke about the way in which 'everything was just coming down around me, and then I ended up just bursting into tears with my head of year and telling her everything' - thereby leading to a referral to mental health services.

Theme Two: Anger and violence towards self and others: 'I feel bad because I take it out on people or myself' (Mikayla, 14)

Whether through their tone of voice during the interview or what they actually said, many of the participants in this study reported feelings of anger and aggression, either directed at others or at themselves. Young people spoke about feeling 'short 
tempered', 'snappy', 'really angry', ‘easily irritable', having 'a short fuse', and getting into 'lots of arguments'. For some, the feeling of anger was what they meant by 'depression'. For example Carl (13), when asked what it was like when he felt depressed, replied 'like my tummy squeezes, it tells me I am more angry, and I need to cool down'.

Although a few described their aggressive outbursts as triggered by a provocation, such as teasing or bullying, others emphasised that the anger came from nowhere, and was not something that they had any choice about. Mikayla (14) was typical of our participants when she explained that she didn't feel she could control her anger:

Just stupid little things like if someone like for example pokes me for ages, I feel really angry, I don't know it just like little things that get me irritable and then if they keep repeating them then I'll go like literally go mad ... It's like I shout at them or punch things or just say stuff I don't even like really mean ... I've even punched a car before.

Young people spoke of how they 'shout and scream and sometimes throw stuff' (Michelle, 14), or become 'extremely aggressive to teachers' (Aqwasi, 15) or with parents (e.g. Rihanna, 15). Kyle (11), for example, spoke of the way that he gets 'angry very easily', and that this quickly turns into violence, with him hitting people, throwing things 'and sometimes I strangle them'. Kyle had hit a teacher with a baseball bat, and another young person had threatened a family member with a knife (Carl, 13).

For others, there seemed to be a movement between feeling (and being) angry and aggressive towards others, and turning that aggression towards themselves. Hayley (17), for example, spoke of the way in which she would take her anger out on herself, describing how she would 'punch walls and nearly break my knuckles because I was angry, but I didn't want to take it out on anyone else'. She spoke of worries that she would 'end up lashing out at someone or hurting someone in college' and immediately went on to say that she had been slicing her wrists and had scars as a result - as if the anger towards others and herself were somehow linked, where self-harm was an outlet for this. Others spoke about pulling out their hair (Mitch, female, 17) or their eye-lashes (Sofia, 17), and conveyed a sense that self-inflicted pain was an attack upon the self that they deeply disliked.

Many young people who spoke about being violent, expressed a wish to stop being so angry. Being angry and violent left many of them 'even more sad' (Ayla, 17) or feeling bad about themselves. For example, Isabella (12) described an incident when she had turned on a girl who had been making fun of her about her mother's death, and physically attacked her. She commented 'I felt myself then turning into a very horrible person. It's like where I was being bullied I felt I was turning into a bully but didn't want to turn into a bully'. This sense of being a 'bad' person - or not wanting to become such a person - is linked to our next theme.

Theme Three: A bleak view of everything: 'I feel like my heart is broken ... but somehow I was the one who broke it' (Brian, 12)

Most participants described negative thoughts that preoccupied them. Young people described life as 'pointless' (Talia, 14), 'grey and just dull' (Lana, 14), with 'no hope at all' (Harriet, 17). 'I do always try to look on the darker side of things really', explained Craig (17), '[I] don't really look on the bright side'. Shauna (14) spoke about how, when her difficulties first began, she 'started worrying about everything and that I could never have a positive look on things, like even when people try and cheer me up and when people tell me things are going to be okay, I don't believe them'.

This negativity was associated with a loss of energy and interest in daily life, often described in terms of feelings of tiredness and difficulties in sleeping. 'I was always really tired and I had no energy to do anything', explained Jade (16). Young people used terms such as 'lethargic', 'tired', and 'can't be bothered', and spoke about the physical sense of being 'weak' or 'exhausted'. Poppy described 'I don't really go out that much anymore, I don't really, I don't exercise as I should ... I can't be bothered, I can't be bothered putting on make-up, even having a bath' (Poppy, 17). Many young people spoke about staying in bed for much of the day, or finding it difficult to get out of bed. 'If I'm going to feel really, really bad,' explained Talia (14), 'I'd rather feel really, really bad in bed'.

The most striking aspect of this bleak view of everything was the way young people spoke about themselves. 'I'm not good enough' (Nicole, 17), 'there's something wrong with me' (Jade, 16), 'useless' (Ayla, 17), 'I'm going to fail in everything' (Nicole, 14), ‘you just feel really worthless .... disappointed with myself ... like a failure’ (Hayley, 17).

Many young people blamed themselves for their problems. Some conveyed a sense that they had a problem in their intrinsic personality - 'I'm kind of a difficult person' (Freddy, 17), 'I think I am selfish' (Jenny, 15), 'I'm an idiot, ugly, stuff like that' (Poppy, 17). Others suggested that the way they were behaving and feeling now was not how they 'really' are, or not how they used to be. A few people spoke about feeling 'not like myself' (Ada, 17) or compared how they were now to how they used to be. 'I don't feel like me anymore', explained Mikayla (14), whilst Poppy (17) told us 'My depression is like a different person ... it's like although it's me, it's like it's part of my personality but it's become it's like it's overshadowing who I am'.

Ayla (17) spoke of how she feared that poor exam results would trigger a feeling that she was a failure, and that she might have 'done something stupid or tried to hurt myself on purpose'. In order to avoid this happening, Ayla (17) deliberately went to stay with friends on the day that the exam results arrived, to prevent herself from self-harming.

Theme Four: Isolation and cutting off from the world - 'Even when I'm with people, I still feel alone' (Nicole, 17)

Most young people described a sense of isolation from others, either through active withdrawal or through experiences of rejection. The sense of isolation was evident in phrases such as 'I just feel like nobody understands what I am going through' 
(Hannah, 16), 'I feel like I'm in prison' (Hayley, 17), 'I feel like I'm in a box .... and there's no way to really get out' (Eleni, 13), 'I'm separated from everyone else' (Freddy, 17), or 'I forget that everyone else exists ... I'm invisible - and I like that' (Mina, 17). Those who did describe having friends saw them as important and helpful, but for many - even if they had been popular and sociable before - they had withdrawn or cut themselves off from their peers. 'I used to be a really good friend and now I'm not', said Sabrina (17), 'I feel like they really do deserve better and I'm just kind of eating away at their time and their happiness'.

Some described how it could feel better to be away from the world and from peers, because being around others was so emotionally draining. 'I come home it's just kind of like a relief', explained Lana (14), who had been bullied at school. Those who had experienced bullying were especially cautious about trying to make links with other people. As Brian (12) put it, 'what's the point of like even trying to make any friends at all, if they are only ever going to hurt me, or turn their back on me'.

But for others, withdrawing from the world, or staying at home alone, was not experienced as a 'solution' to their problems; for many young people, this only made things worse. For Megan (14), staying at home in her room 'makes it more down because I think about everything and then I'm just like really more upset'; whilst Mina (17) recounted a specific incident that seemed to sum up the dilemma for many of the young people we spoke to:

Like on Saturday it was like a friend's birthday and I was like 'ok, I'm gonna go because you know, I should go', so I went and then like, for an hour or two I was you know ok, I talked to like two people which is quite an achievement and ... but then I just I just excused myself and like - I didn't - I just lay down on her couch and refused to speak to anyone I just couldn't there were just too many people ... but then it's - but then on the other hand sometimes when some of my friends are like, they just don't - they're ok with ignoring me, with not asking about it, I feel like kind of - I know it's ridiculous, but unloved.

A few young people spoke about parents being supportive and them being able to talk about their problems with a parent, but for many there was a similar sense of isolation and withdrawal in relation to family, as there was with peers. 'My parents don't fully understand most of the time', said Leila (17), 'cos I can't really explain it to them'. 'I'll just shut myself in my room', said Lauren (17), 'and not talk to anyone for ages'. There was a sense that young people felt a lack of emotional understanding. For example, Martin (17) spoke about his referral to child and adolescent mental health services, 'My mum and dad know I come here ... but they don't really know anything about me'.

There were differences in the reasons young people cut themselves off from their parents. A few young people, like Sabrina (17), actively stopped talking to their parents, as 'what they don't know won't hurt them'; while for others, like Connor (17), there was a sense that his mother didn't understand what he was going through, so would be critical or annoyed with him, 'so I just [try] to avoid her and stuff and avoiding everyone really'.

Theme Five: The impact on education - 'I can't learn anything' (Harriet, 17)

Not surprisingly, the lack of energy, loss of interest and wish to withdraw from the world also affected most of our participants' educational progress and experience of school. One participant, Ada (17), spoke about school being the 'last thing I was holding onto, to kind of keep me going'; but this was not an experience shared by most of the participants. The majority of young people in our study spoke about struggles with getting up in the morning to attend school or college, of losing interest and motivation in learning, of grades getting worse and of finding it hard to be around other people. Rihanna (15), for example, explained:

I used to just like really enjoy school and like ... cos I'm - I get my grades, I get A's all the time and stuff but then like, I just couldn't be bothered no more, like I hated going to school and ... then I'd get irritated, then I'd just start talking or misbehaving so I can get sent out so I can just - go home or whatever.

Young people reported problems with getting to school, and some had dropped out of school all together. Those who were still going spoke about how hard it was, and for a few this was because they got into extreme anxiety states. Harriet (17), for example, spoke about how she would 'get panicky so I can't learn anything', while Sabrina (17) spoke about feeling so 'overwhelmed' at school that she had to 'take myself away and just stay in the bathroom for however long'. Ada (17), who had stopped attending school completely, remembered that she 'felt really scared to be like around people', and reached the point where she was having panic attacks at school.

Although anxiety impacted on education, the most common problem that young people spoke about in relation to school was difficulty with focus or concentration. 'I just can't concentrate [on] anything anymore', explained Eleni (13), while Amy (14) spoke about the way that one of her teachers simply lets her sleep during lessons 'cos I don't listen or I'm walking out - so if I wake up, she'll tell me to go back to sleep'. The difficulties with concentration that young people spoke about went handin-hand with other problems, which made the whole experience of engaging with education an ordeal:

At school I can never get up so I'm always late for school and come really late - like I would miss two lessons and then I come in, and then when I am in lessons I don't concentrate and then I - you know I get really behind on my work, homework and things I don't really do it (Jade, 16).

Participants explained their difficulties with concentration in a number of different ways. Some described it like "blank [ing] out' (Aleksander, 16) or simply losing interest in what they were doing (e.g. Maggie, 15); for others, the difficulty seemed 
to be more anxiety-driven. Amy (14), for example, spoke about the way she would 'keep thinking about ... what they gonna make me do, and then if I'm not gonna do it, what's gonna happen' - and this anxiety itself made it impossible to concentrate on her work. Ayla (17) described how, when she was supposed to be concentrating on schoolwork, 'I'd just think about ways that I could die just right then'. Such difficulties with concentration in turn led to more problems: the participants in our study reported feeling more 'stressed', more depressed about their situation, and more unhappy or annoyed with themselves and with those around them.

\section{Discussion}

Despite the fact that the interviews used in this study were conducted at a point where the young people were often severely depressed, and had yet to receive any professional help, they were remarkably articulate about their experiences of depression. In many respects, their subjective accounts confirmed the view held within academic psychiatry that the "core features' of a major depressive episode are comparable for young people and adults. However it was noticeable that change in appetite and weight (one of the nine symptoms of major depression in DSM-5; American Psychiatric Association, 2013) was rarely mentioned by our participants - a similar finding to Lachal et al. (2012), who noted that the participants in their study made no mention of eating disturbances. (A diagnosable eating disorder was an exclusion criterion for our study, but in adults a change in the pattern of eating or weight loss - short of formal eating disorder - is among the core biological symptoms of clinical depression). All of the other key features - depressed mood, loss of interest or pleasure, change in sleep patterns, low energy, low self-esteem, poor concentration and thoughts of suicide or death - were prominent in the accounts given by young people. The degree of suffering described by our participants leaves no doubts about the reality and seriousness of adolescent depression, and supports the findings of earlier qualitative studies (e.g. Bury, Raval, \& Lyon, 2007).

Our first and third themes ('misery, despair and tears' and 'a bleak view of everything') challenge the view set out by some previous studies; that young people are less likely than adults to explicitly complain of low mood, or describe their sadness, pessimism or tearfulness (Cook et al., 2009; Farmer, 2002; Lachal et al., 2012). Across the age group (11-17) and both genders, the participants powerfully described the despair, sadness and hopelessness that they were experiencing. It may be that the difference is because the young people in our study had all been recognised and referred for treatment of depression, and so were to some degree ready to speak about their emotional experiences; or it could be that there were real qualitative differences in the experience of depression among our participants compared to previous studies. However, recent findings from the Great Smoky Mountains prospective population-based study showed that depressed mood is the most common cardinal mood in youth meeting criteria for depression (Stringaris et al., 2013), and that young people can experience such low mood as powerfully as adults. As with Lachal et al. (2012), the 'overwhelming' nature of the subjective experience of depression among the participants in our study was striking.

Since the introduction of DSM-III, 'irritability' has been seen as an adolescent-specific feature of depression, of equal significance to 'low mood' in the diagnosis of depression in youth (American Psychiatric Association, 1980). Our second theme, 'anger and violence towards self and others', support the view of the centrality of irritability, although the degree of anger described by our participants seems to go beyond what is usually meant by the term 'irritability'. This supports other studies which have found anger and irritability to be the most commonly reported emotional experiences in clinically depressed adolescents (Hammen \& Compas, 1994; Lachal et al., 2012) and the 'unrelenting anger' described by Farmer (2002, p.10). These cumulative findings indicate that anger may be a more significant element of youth depression than the psychiatric literature has previously suggested. Interestingly, a relatively small proportion of our participants met diagnostic criteria for oppositional defiant disorder (12\%) and none for conduct disorder, suggesting that the anger experienced by them has characteristics specific to depression.

Our fourth and fifth themes, 'isolation and cutting off from the world' and 'impact on education', support the findings from earlier qualitative studies, in which 'emotional homelessness' (Farmer, 2002), 'spiralling down and within' (Dundon, 2006), 'loneliness' (Lachal et al., 2012) and 'withdrawal' (McCann et al., 2012) were identified as key elements of the experience of depression in young people. Crowe and colleagues also identified social withdrawal (for boys) and loneliness (for girls) as the most common characteristics described by depressed youth which are not core diagnostic features of depression (Crowe et al., 2006), although social isolation may be picked up as an aspect of 'impairment in social functioning'. The specific impact on education - both socially and in terms of academic achievement - indicates the importance of considering the school environment when designing interventions for adolescent depression.

Some aspects of the experiences of adolescents map on well to items in commonly used screening tools for depression, such as the Moods and Feelings Questionnaire (MFQ), which includes items covering the themes 'Misery, despair and tears' (e.g. item 1: "I felt miserable or unhappy), 'A bleak view of everything' (e.g. item 15: "I thought there was nothing good for me in the future") and 'Isolation and cutting off from the world'(e.g. item 20: "I didn't want to see my friends"). Interestingly, while isolation and loneliness is captured in the MFQ and the Child Depression Inventory (CDI, where items include "I do not want to be with people at all" and "I feel alone all the time"; Kovacs, 1983), isolation is not included in DSM-5 criteria for major depression (American Psychiatric Association, 2013), yet formed an important part of young people's experiences. This suggests isolation may present as an important warning sign for depression.

While aspects of young people's experiences of depression fitted with DSM-5 criteria for major depression (American Psychiatric Association, 2013), we found some key parts of their experiences were not accounted for in diagnostic criteria and screening tools for depression. While "irritability" is included in DSM-5 criteria for major depression (American 
Psychiatric Association, 2013), what young people described in our study went far beyond irritability; they spoke of explosive anger, rage or violence that was out of control, which came out of nowhere, which is not captured in screening tools for depression. DSM-5 does not define irritability, nor does it offer examples of how irritability may present, whereas indicators of depressed mood are outlined: "depressed mood most of the day, nearly every day, as indicated by either subjective report (e.g., feels sad or empty) or observation made by others (e.g., appears tearful)" (American Psychiatric Association, 2013). No such indicators are offered for irritability, leaving this criteria open to the interpretation of professionals. It seems important that key terms in diagnostic criteria, such as "irritability", are unpacked so that criteria is transparent and can be easily understood by professionals. For example, should expressions of anger be considered as "irritability", or does anger represent a construct distinct to irritability? Criteria should utilise the language of young people to help bridge the gap between young people's experiences with how professionals understand diagnoses.

Screening tools for depression are limited in how much attention they pay to irritability (which is surprising, given that DSM-5 gives irritability equal weight to low mood; American Psychiatric Association, 2013). Irritability is not included in the Revised Children's Anxiety and Depression Scale (RCADFS, Chorpita, Yim, Moffitt, Umemoto, \& Francis, 2000), and only one item in the CDI relates to feelings of irritability: "I get into fights all the time" (Kovacs, 1983). While this item may capture some of the externalised anger that our participants described, it does not account for the internal feelings of anger or anger they turned on themselves. Similarly, the MFQ includes one single question relating to irritability: "I got grumpy and cross easily" (Angold et al., 1987). The words "grumpy" and "cross" did not come up in a single interview with the 77 young people who took part in our study, and we must question if young people relate to these words and how well they fit with their experiences. If the language in these self-report measures does not make sense to young people, there is a significant risk that these measures will fail to pick up the difficulties that young people are experiencing, or the extent of their difficulties. Therefore the development of such measures should be guided by the language and experiences of young people themselves, to ensure they are relevant and meaningful to the population they are designed for.

The impact on school and education was prominent in the experiences of young people. The RCADS does not have any items relating to school experiences (Chorpita et al., 2000), while the MFQ has one item relating to impact on concentration (which was a significant part of young people's difficulties in school), and another item about enjoyment in school: "I didn't have any fun at school/college/work" (Angold et al., 1987). Arguably, most adolescents may not consider school to be "fun"; this is unlikely to be specific to adolescents suffering from depression. The experiences of young people in school in our study went far beyond not having fun; we learnt from them about the significant struggle the faced to get to school, the pressure they were under with schoolwork and the difficulty they faced in being around people at school. These findings suggest that elements of screening tools are outdated, and should be updated to fit with the difficulties young people experience in the present day.

\section{Conclusion}

The current study provides an overview of the experiences of depression in a sub-group of adolescents taking part in a clinical trial, prior to starting treatment. Although broadly reflecting existing models of youth depression, the findings from this study show that anger and a sense of isolation were prominent features of young people's experience, and are potentially important warning signs for depression; yet these experiences are not diagnostic criteria for depression in young people.

A greater awareness of these aspects of depression, based on the descriptions of depressed adolescents themselves, may assist in helping to detect and diagnose depression more accurately. To improve detection, measures for adolescent depression should be developed to fit the pattern of depression described by young people, as has been the case with the relatively recently developed Adolescent Depression Rating Scale which was developed in a sample of French adolescents (ADRS; Revah-Levy, Birmaher, Gasquet, \& Falissard, 2007). An implication of this study is that commonly-used screening questionnaires, such as the CDI (Kovacs, 1983) RCADS (Chorpita et al., 2000) and MFQ (Angold et al., 1987), may be missing some important features central to adolescents' experiences of depression. Development of measures should be informed by the language young people use themselves, to find a shared language and understanding between young people and professionals. Education is required for young people, their parents, teachers and health professionals, to improve awareness of warning signs for depression, to ensure that young people get the help they need.

\section{Strengths and limitations of this study}

The strengths of this study are the large sample which has enabled us to develop a robust understanding of young people's experience of depression, allowing for open-ended reporting of subjective experiences from the perspective of young people themselves. However, it is important to be aware of the limitations of the study. Young people had sought professional help for their difficulties, and met criteria for DSM-IV major depression according to the K-SADS-PL (Kaufman et al., 1997). This may have restricted the range of experiences described by young people, by excluding those who did not meet inclusion criteria for the trial. Therefore the study may not be representative of the significant proportion of depressed adolescents who do not seek professional help or whose depression goes unrecognised, and there is a risk that the themes developed may be less generalisable to the experience of those young people whose depression does not fit so clearly within DSM-IV criteria. The sample may comprise of adolescents whose difficulties were externalised, who are typically more likely to be recognised as needing help, whereas those who internalise their difficulties are more difficult to recognise and may not be well 
represented in our sample (Dwyer, Nicholson, \& Battistutta, 2006). It should also be kept in mind that the findings were based on young people in the UK only, which may differ from the experiences of young people in other parts of the world.

\section{Directions for future research}

This study highlights the need to better understand adolescent depression. Future research should focus on developing measures for depression which match the experiences of depression described by adolescents, and to explore how specific aspects of young people's experiences of depression can inform treatment preferences, engagement and outcomes. As these interviews were conducted as part of a longitudinal study, the next step for our team will be to explore how young people's experience of depression changes over time, and whether the way in which participants experience depression influences how they engage with treatment. Future work will include the perspectives of parents and therapists; whilst mixed-method studies, drawing on data from IMPACT-ME alongside outcome data from the IMPACT clinical trial, will make it possible to relate the young people's subjective accounts of depression with data gathered using standardised measures (e.g. MFQ; Angold et al., 1987). We hope this will make it possible to achieve a more nuanced understanding of adolescent depression, in a way which puts their subjective experience - so central to any meaningful psychological intervention - at the heart of our understanding.

\section{Declaration of conflicting interests}

The authors declare no potential conflicts of interest with respect to the research, authorship, and/or publication of this article.

\section{Acknowledgements}

The IMPACT-ME study was supported by a grant from the Monument Trust (grant reference: MON5229), which the present research is part of.

\section{References}

American Psychiatric Association. (1980). Diagnostic and statistical manual of mental disorders, Third Edition (DSM-III). Washington DC: APA.

American Psychiatric Association. (2000). Diagnostic and statistical manual of mental disorders, Fourth Edition, Text Revision (DSM-IV-TR). Washington DC: APA.

American Psychiatric Association. (2013). Diagnostic and statistical manual of mental disorders, Fifth Edition (DSM-5). Washington DC: APA.

Angold, A., Costello, E., Pickles, A., \& Winder, F. (1987). The development of a questionnaire for use in epidemiological studies in children and adolescents. MRC Child Psychiatry Research Unit.

Bazeley, P., \& Jackson, K. (2013). Qualitative data analysis with NVivo (Vol. 2). London: Sage Publications.

Birmaher, B., Brent, D., Bernet, W., Bukstein, O., Walter, H., Benson, R. S., et al. (2007). Practice parameter for the assessment and treatment of children and adolescents with depressive disorders. Journal of the American Academy of Child and Adolescent Psychiatry, 46(11), 1503-1526. http://dx.doi.org/10.1097/ chi.0b013e318145ae1c.

Bury, C., Raval, H., \& Lyon, L. (2007). Young people's experiences of individual psychoanalytic psychotherapy. Psychology and Psychotherapy, 80, 79-96.

Chorpita, B. F., Yim, L., Moffitt, C., Umemoto, L. A., \& Francis, S. E. (2000). Assessment of symptoms of DSM-IV anxiety and depression in children: a revised child anxiety and depression scale. Behaviour Research and Therapy, 38(8), 835-855. http://dx.doi.org/10.1016/S0005-7967(99)00130-8.

Cicchetti, D., \& Toth, S. L. (1998). The development of depression in children and adolescents. The American Psychologist, 53, $221-241$.

Cook, M. N., Peterson, J., \& Sheldon, C. (2009). Adolescent depression: an update and guide to clinical decision making. Psychiatry, 6, $17-31$.

Costello, E., Erkanli, A., \& Angold, A. (2006). Is there an epidemic of child or adolescent depression? Journal of Child Psychology and Psychiatry and Allied Disciplines, 47(12), 1263-1271. http://dx.doi.org/10.1111/j.1469-7610.2006.01682.x.

Crowe, M., Ward, N., Dunnachie, B., \& Roberts, M. (2006). Characteristics of adolescent depression. International Journal of Mental Health Nursing, 15, 10-18.

Dundon, E. E. (2006). Adolescent depression: a metasynthesis. Journal of Pediatric Health Care, 20, $384-392$.

Dwyer, S. B., Nicholson, J. M., \& Battistutta, D. (2006). Parent and teacher identification of children at risk of developing internalizing or externalizing mental health problems: a comparison of screening methods. Prevention Science, 7(4), 343-357.

Elliott, R., Slatick, E., \& Urman, M. (2001). Qualitative change process research on psychotherapy: alternative strategies. In Qualitative psychotherapy research - Methods and methodology (pp. 69-111). Lengerich, Germany: Pabst Science.

Farmer, T. J. (2002). The experience of major depression: adolescents' perspectives. Issues in Mental Health Nursing, 23, $567-585$.

Goodyer, I. M., Tsancheva, S., Byford, S., Dubicka, B., Hill, J., Kelvin, R., et al. (2011). Improving mood with psychoanalytic and cognitive therapies (IMPACT): a pragmatic effectiveness superiority trial to investigate whether specialised psychological treatment reduces the risk for relapse in adolescents with moderate to severe unipolar depression. Trials, 12(1), 175.

Hall, G. S. (1904). Adolescence: Its psychology and its relations to physiology, anthropology, sociology, sex, crime, religion, and education (Vols. I \& II). New York: D. Appleton \& Co.

Hammen, C., \& Compas, B. E. (1994). Unmasking unmasked depression in children and adolescents: the problem of comorbidity. Clinical Psychology Review 14, 586-603.

Johnston, B. M., Milligan, S., Foster, C., \& Kearney, N. (2012). Self-care and end of life care-patients' and careers' experience a qualitative study utilising serial triangulated interviews. Supportive Care in Cancer: Official Journal of the Multinational Association of Supportive Care in Cancer, 20(8), 1619-1627. http:// dx.doi.org/10.1007/s00520-011-1252-3.

Kaufman, J., Birmaher, B., Brent, D., Rao, U., Flynn, C., Moreci, P., et al. (1997). Schedule for Affective Disorders and Schizophrenia for School-Age ChildrenPresent and Lifetime Version (K-SADS-PL): initial reliability and validity data. Journal of the American Academy of Child and Adolescent Psychiatry, 36, 980-988. http://dx.doi.org/10.1097/00004583-199707000-00021.

Kessler, R. C., Avenevoli, S., \& Ries Merikangas, K. (2001). Mood disorders in children and adolescents: an epidemiologic perspective. Biological Psychiatry, 49, $1002-1014$

Kovacs, M. (1983). The Children's Depression Inventory: A self-rated depression scale for school-aged youngsters. Pittsburgh, PA: University of Pittsburgh School of Medicine. 
Lachal, J., Speranza, M., Schmitt, A., Spodenkiewicz, M., Falissard, B., Moro, M.-R., et al. (2012). Depression in adolescence: from qualitative research to measurement. Adolescent Psychiatry, 2(4), 296-308.

Martinez, R., Reynolds, S., \& Howe, A. (2006). Factors that influence the detection of psychological problems in adolescents attending general practices. British Journal of General Practice, 56, 594-599.

McCann, T. V., Lubman, D. I., \& Clark, E. (2012). The experience of young people with depression: a qualitative study. Journal of Psychiatric and Mental Health Nursing, 19(4), 334-340.

Midgley, N., Ansaldo, F., Parkinson, S., Holmes, J., Stapley, E., \& Target, M. (2011). Expectations of therapy interview (Young person and parent versions). Unpublished manuscript. London: Anna Freud Centre.

Midgley, N., Ansaldo, F., \& Target, M. (2014). The meaningful assessment of therapy outcomes: incorporating a qualitative study into a randomized controlled trial evaluating the treatment of adolescent depression. Psychotherapy, 51(1), 128-137.

Mueller, C., \& Orvaschel, H. (1997). The failure of "adult" interventions with adolescent depression: what does it mean for theory, research and practice? Journal of Affective Disorders, 44, 203-215.

NICE. (2005). Depression in children and young people: Identification and management in primary, community and secondary care. London: National Institute for Health and Clinical Excellence.

NICE. (2013). Depression in children and young people: Quality Standards 48. London: National Institute for Health and Clinical Excellence.

Revah-Levy, A., Birmaher, B., Gasquet, I., \& Falissard, B. (2007). The Adolescent Depression Rating Scale (ADRS): a validation study. BMC Psychiatry, 7, 2.

Rey, J., Grayson, D., Mojarrad, T., \& Walter, G. (2002). Changes in the rate of diagnosis of major depression in adolescents following routine use of a Depression Rating Scale. Aust N Z J Psychiatry, 36(2), 229-233.

Richmond, T. K., \& Rosen, D. S. (2005). The treatment of adolescent depression in the era of the black box warning. Current Opinion in Pediatrics, 17(4), 466-472. http://dx.doi.org/10.1097/01.mop.0000166347.53102.e7.

Ritchie, J., \& Spencer, L. (1994). Qualitative data analysis for applied policy research. In Analyzing qualitative data (Vol. 25, pp. 173-194).

Rutter, M. (1980). Changing youth in a changing society: Patterns of adolescent development and disorder. Cambridge: Harvard University Press.

Smith, J. A., Flowers, P., \& Larkin, M. (2009). Interpretative phenomenological analysis: theory, method and research. In Learning (Vol. 9, p. 225). London: Sage.

Stringaris, A., Maughan, B., Copeland, W. S., Costello, E. J., \& Angold, A. (2013). Irritable mood as a symptom of depression in youth: prevalence, developmental, and clinical correlates in the Great Smoky Mountains Study. Journal of the American Academy of Child and Adolescent Psychiatry, 52(8), $831-840$

Ward, D. J., Furber, C., Tierney, S., \& Swallow, V. (2013). Using framework analysis in nursing research: a worked example. Journal of Advanced Nursing, 69(11), 2423-2431. http://dx.doi.org/10.1111/jan.12127.

Weissman, M. M., Wolk, S., Goldstein, R. B., Moreau, D., Adams, P., Greenwald, S., et al. (1999). Depressed adolescents grown up. JAMA: The Journal of the American Medical Association, 281(18), 1707-1713. http://dx.doi.org/10.1001/jama.281.18.1707.

Werbart, A., \& Levander, S. (2005). Understanding the incomprehensible: private theories of first-episode psychotic patients and their therapists. Bulletin of the Menninger Clinic, 69, 103-136.

Williams, S. B., O'Connor, E. A., Eder, M., \& Whitlock, E. P. (2009). Screening for child and adolescent depression in primary care settings: a systematic evidence review for the US Preventive Services Task Force. Pediatrics, 123(4), e716-e735.

World Health Organization. (1993). The ICD-10 classification of mental and behavioural disorders: Diagnostic criteria for research. The ICD-10 classification of mental and behavioural disorders: Diagnostic criteria for research. Geneva: WHO. 